\title{
Achalasia associated with neurofibromatosis
}

\author{
STEPHEN N SULLIVAN, MD, FRCPC, FRCP(LOND)
}

SN SUllivan. Achalasia associated with neurofibromatosis. Can J Gastroenterol 1991;5(2):67-68. A 32-year-old patient with neurofibromatosis who developed achalasia is reported. At the second pneumatic dilation the esophagus was perforated, requiring surgical repair and myotomy. The patient made an uneventful recovery and now swallows without difficulty. This is the second report of this association.

Key Words: Achalasia, Esophagus, Neurofibromatosis, von Recklinghausen's disease

\section{Achalasie et neurofibromatose}

RESUME: On rapporte le cas d'un patient de 32 ans atteint de neurofibromatose et qui a développé une achalasie. Une perforation de l'oesophage est survenue à la seconde dilatation pneumatique et a nécessité une réparation chirurgicale et une myotomie. Après des suites opératoires simples, le patient peut maintenant avaler sans difficulté. Cette association est rapportée pour la seconde fois.
$S^{v+n}$ YMPTOMATIC GASTROINTESTINAL involvement in neurofibromatosis, or von Recklinghausen's disease, is uncommon $(1,2)$. Tumours of neurogenic origin may bleed or obstruct by intussusception. An association with adenocarcinoma of the intestine has also been reported $(3,4)$. Megacolon from involvement of the autonomic nervous system has been described (5-9), and there has been one report of achalasia associated with neurofibromatosis (10). The author reports another patient with the concurrence of these two very rare diseases.

\section{CASE PRESENTATION}

A 32-year-old woman presented with a one to two year history of slowly progressive dysphagia for solids and liquids. The dysphagia was associated with a retrosternal pressure-like pain which would be relieved suddenly as food and fluid left her esophagus, or if she induced vomiting. She also complained of postural regurgitation of recently eaten food.

She had been diagnosed at age three years as having neurofibromatosis. The major manifestation had been cutaneous lesions - café-au-lait spots and
Gastrointestinal Unit, Victoria Hospital, London, Ontario

Correspondence and reprints: Dr SN Sullivan, Gastrointestinal Unit, Victoria Hospital,

South Street Campus, London, Ontario N6A 4 G5

Received for publication June 1, 1990. Accepted November 6, 1990 neurofibromas. She had had a number of plastic surgical procedures for removal of facial neurofibromas. There was no family history of neurofibromatosis.

On physical examination the only abnormalities were numerous, raised, slightly pigmented neurofibromas and flat pigmented lesions which were hirsute (Figure 1).

A barium swallow revealed slight dilation of the body of the esophagus with incomplete opening of the lower esophageal sphincter.

At endoscopy the esophagus was filled with frothy saliva, but no food. The lower esophageal sphincter was tightly closed, but allowed the passage of the endoscope with minimal resistance. There was no evidence of a mass lesion in the distal esophagus or at the cardia. The esophagus could be fully inflated with air, and there was no motor activity, other than some tertiary contractions.

At esophageal manometry the lower esophageal sphincter had a pressure of $30 \mathrm{mmHg}$ above intragastric pressure. With both wet and dry swallows there was complete absence of peristalsis in the body of the esophagus and failure of relaxation of the sphincter. In the body of the esophagus there were numerous low pressure tertiary contractions and, on a couple of occasions, wet swallows induced long duration tertiary contractions with amplitudes up to $40 \mathrm{mmHg}$. 
The patient underwent pneumatic dilation with a $30 \mathrm{~mm}$ Rigiflex pneumatic dilator. There was complete resolution of the dysphagia for approximately three months when the symptoms gradually returned, and she attended for repeat pneumatic dilation. Unfortunately, at the time of dilation the esophagus was perforated. Surgical repair and myotomy was necessary. At the time of thoracotomy no neurofibromas were evident in the mediastinum or in the wall of the esophagus. After surgery the patient made an uneventful recovery and now swallows without difficulty.

\section{DISCUSSION}

Is there an association between neurofibromatosis and achalasia? Both are uncommon conditions. Neurofibromatosis is a dominantly inherited neuroectodermal dysplasia which occurs in approximately one in 3000 births. Achalasia is an acquired condition of unknown etiology with an incidence of approximately one in 100,000 . There is no reason why the two conditions could not occur by chance alône in the same individual, but that would be a very rare event. A cause and effect relationship is sup-

\section{REFERENCES}

1. Hochberg FH, DaSilva AB, Galdabini J, Richardson EP. Gastrointestinal involvement in von Recklinghausen's neurofibromatosis. Neurology 1974;24:1144-51.

2. Petersen JM, Ferguson DR. Gastrointestinal neurofibromatosis. J Clin Gastroenterol 1984:6:529-34.

3. Nelson AM. Small bowel adenocarcinoma associated with neurofibromatosis. Am J Gastroenterol 1982;77:149-51.

4. Jones T], Marshall TL. Neurofibromatosis and small bowel adenocarcinoma: An unrecognized

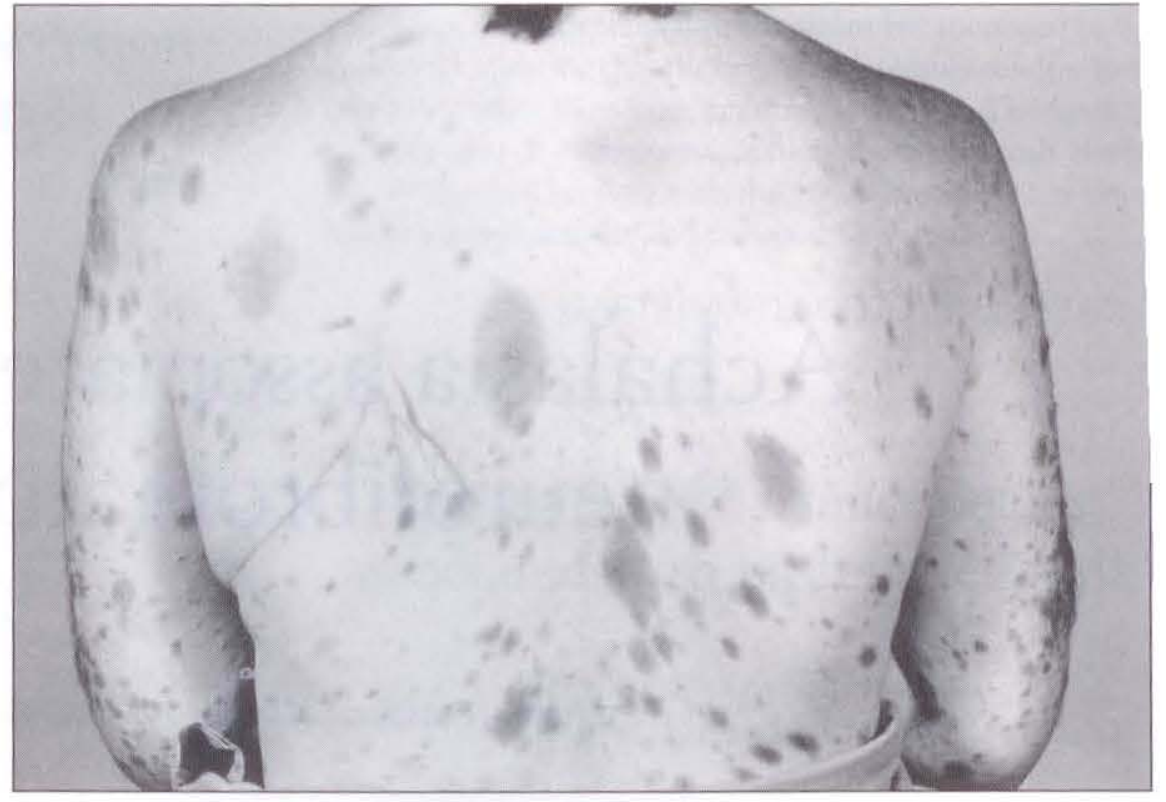

Figure 1) Patient's cutaneous stigmata of neurofibromatosis

ported by the well established association of neurofibromatosis with megacolon (5-9) and with bladder dysfunction $(10,11)$. Since this is the second report of achalasia and neurofibromatosis occurring together, it would be worthwhile looking for subtle hints of neurofibromatosis in patients with achalasia. This might consist solely of café-au-lait spots, or perhaps a few

association. Gut 1987;28:1173-6.

5. Staple TW, McAlister WH, Anderson MS. Plexiform neurofibromatosis of the colon simulating Hirschsprung's disease. Am J Roentgenol 1964;91:840-5.

6. Ternberg JL, Winters K. Plexiform neurofibromatosis of the colon as a cause of congenital megacolon. Am J Surg 1965;109:663-5.

7. Phat VN, Seleur A, Da M, et al. Primary myenteric plexus alterations as a cause of megacolon in von Recklinghausen's disease. Pathol Biol 1980;18:585-8.

8. Saul RA, Sturner RA, Burger PL. Hyperplasia of the myenteric plexus. inconspicuous cutaneous neurofibromas. Likewise, it would be worth asking patients with neurofibromatosis about some of the subtle symptoms of achalasia and perhaps even doing barium swallows, radionuclide esophageal transit studies, or esophageal manometry. This could establish once and for all whether there truly is an association between these two conditions.

Its association with early infantile megacolon and neurofibromatosis. Am J Dis Child 1982;136:852-4.

9. Feinstat $T$, Tesluk H, Schuffler MD, et al. Megacolon and neurofibromatosis: A neuronal intestinal dysplasia. Gastroenterology 1984;86:1573-9.

10. Foster PN, Stewart M, Lowe JS, Atkinson M. Achalasia-like disorder of the esophagus in von Recklinghausen's neurofibromatosis. Gut 1987;28:1522-6.

11. Clark SS, Martlett MM, Prudencio RF. Neurofibromatosis of the bladder in children: Case report and literature review. J Urol 1977;1 18:654-6. 


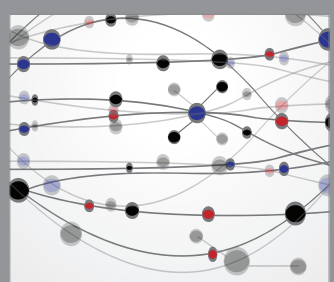

The Scientific World Journal
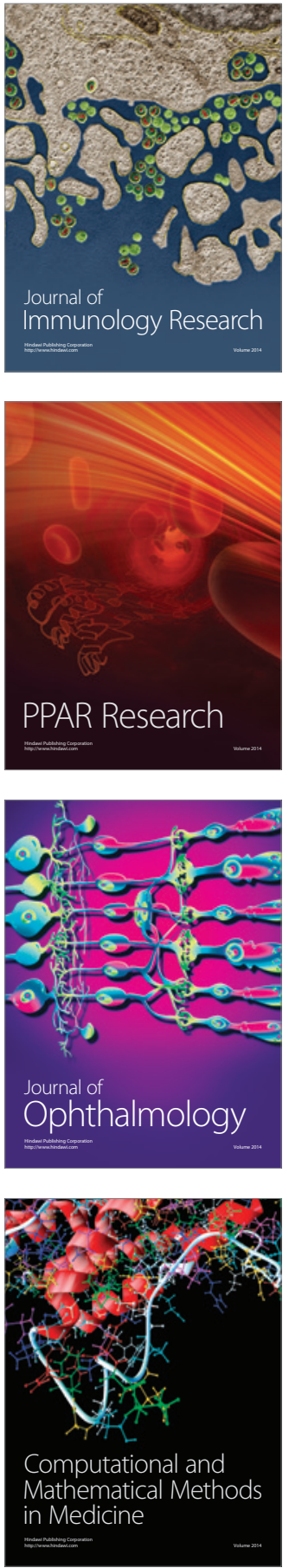

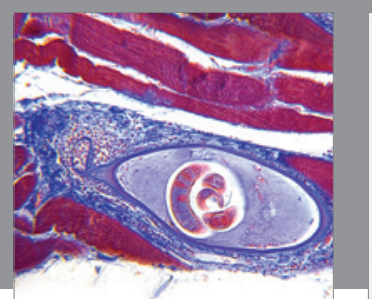

Gastroenterology Research and Practice

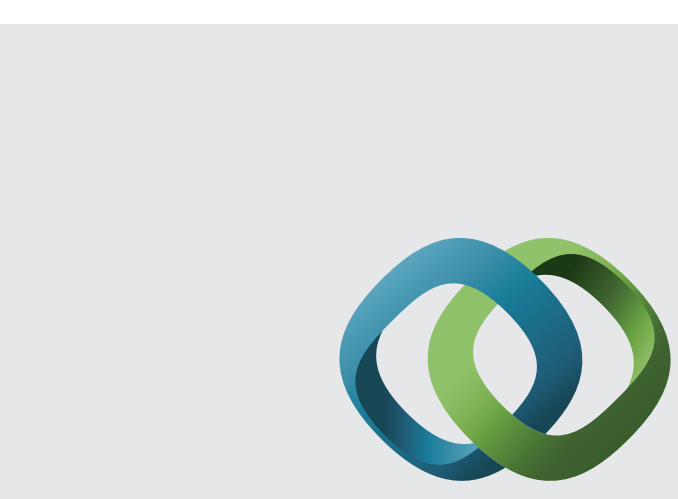

\section{Hindawi}

Submit your manuscripts at

http://www.hindawi.com
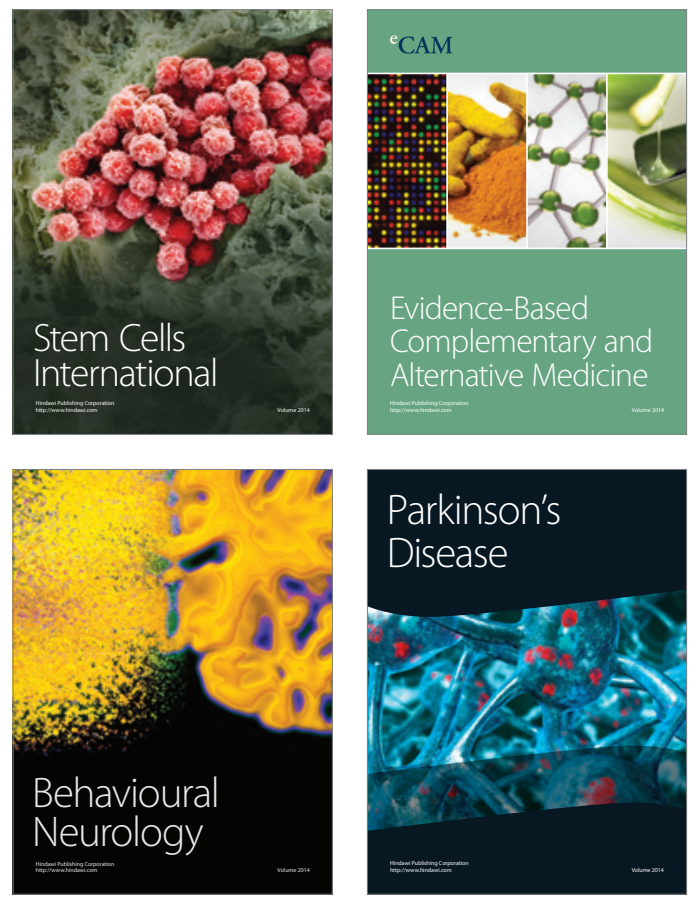
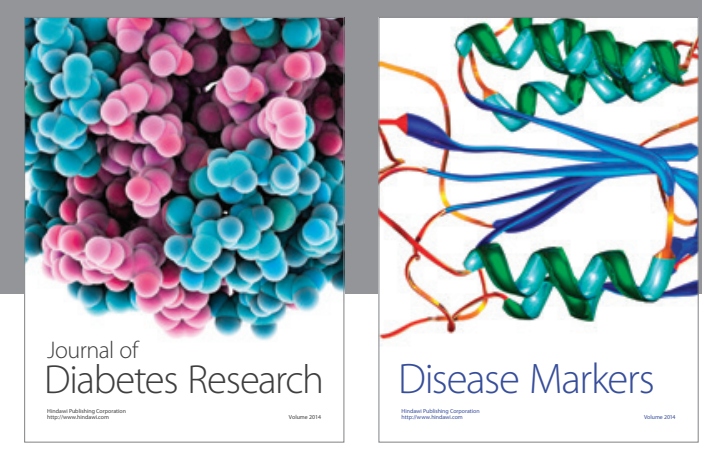

Disease Markers
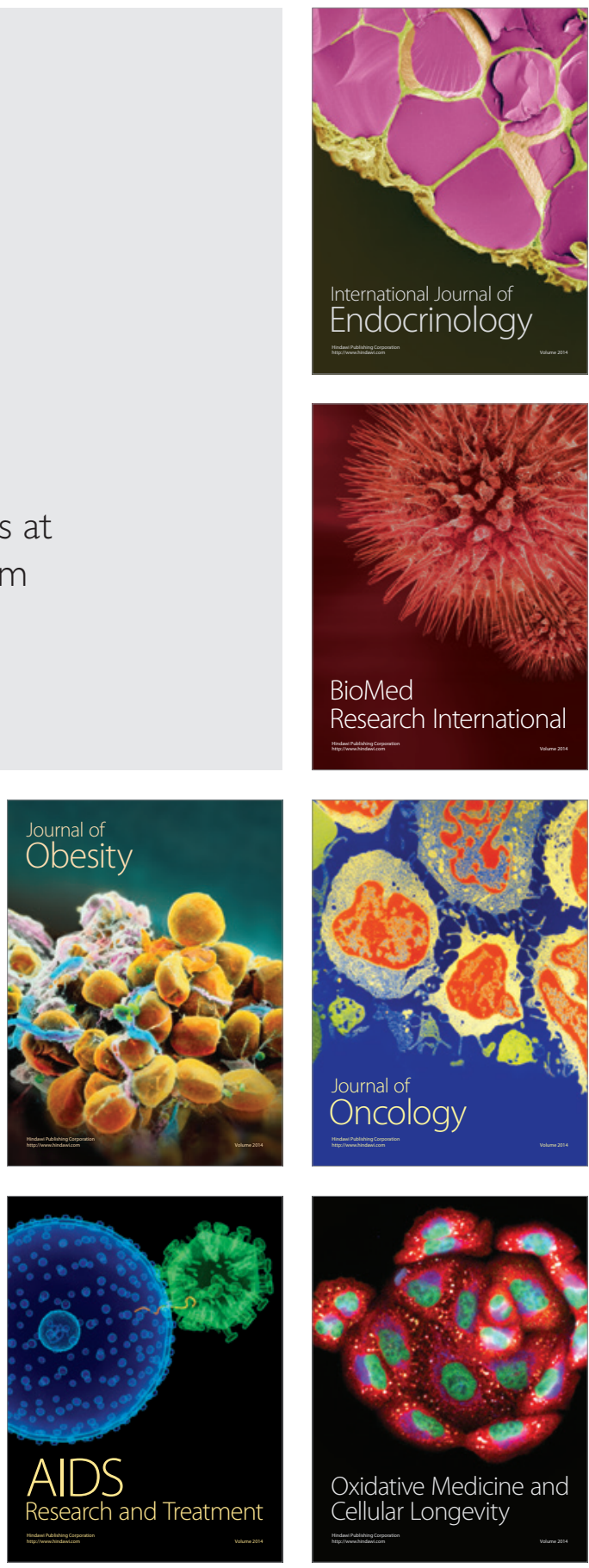